DOI: 10.20472/EFC.2016.006.002

\author{
PHILIPPE ADAIR \\ University Paris-Est Créteil (UPEC), France
}

OKSANA NEZHYVENKO

National University of Kyiv-Mohyla Academy (NaUKMA)., Ukraine

\title{
SEX WORK VS. SEXUAL EXPLOITATION: ASSESSING GUESSTIMATES FOR PROSTITUTION IN THE EUROPEAN UNION
}

\begin{abstract}
:
Prostitution regimes in the EU-28 include prohibition, regulation and abolition; economics literature tackles this typology from the perspective of both free sex work and forced labour trafficking. We review the data sources on the demand-side and the supply-side in order to gauge how large is the sex market and informal employment for sex workers. We calculate Estimates $1 \mathrm{~A}$ and $1 \mathrm{~B}$ from miscellaneous sources, whereas HIV prevalence among sex workers from World Health Organisation provides Estimates $2 \mathrm{~A}$ and 2B. We calculate Estimate 3 from victims of sexual exploitation trafficking according to data collected by the UNODC and Eurostat. We design an OLS model to test the five Estimates of prostitution in EU-28 according to GDP per capita, legislation, supply-side and demand-side variables. Last, we assess which might be the most likely Estimates as regards GDP enhancement in 2010, with respect to National Accounts adjustment for illegal production and consumption expenditure. Hence, we come up with a lower bound Estimate that may be used as a benchmark for macroeconomic policy.
\end{abstract}

\section{Keywords:}

EU-28; informal employment; National Accounts; Non Observed Economy; prostitution; sex work; sexual exploitation trafficking.

JEL Classification: E26, J46, 017 


\section{Introduction}

Prostitution, the controversial so-called "oldest profession", raises moral and economic issues such as social stigma, health risks and tax evasion, echoing the economists (Mandeville, Malthus and Stuart Mill) whose doctrines inspired current legislation regarding prostitution in the European Union (EU-28). Advocacy for laissez-faire (Hakim, 2015) confronts the virtuous stance on abolition (Charpenel, 2013).

Prostitution is back again on the agenda: the EU political arena (Mendez Bota, 2014; Schulze, 2014) discussed the issue, which also deserves special attention from Eurostat since illegal production and namely prostitution is included into the national accounts since 2010. Strangely enough, no assessment has been yet applied to varied expert calculations. It is our purpose to fill the gap and provide a tentative benchmark for the EU-28, wherein three different policy regimes rule prostitution: prohibition, regulation and abolition, which all ban human trafficking for sexual exploitation.

Prohibition makes prostitution illegal as well as the prostitute liable to penalties in four Member States (Croatia, Lithuania, Malta and Romania until decriminalisation in 2013), which account for 1.63 percent of EU GDP and 5.5 percent of total population of the EU-28 in 2010.

As for regulation, in line with Mandeville (1724), prostitution is a legal trade in brothels, including tax collection and labour contracts for sex workers, in four Member States, which contribute 29.2 percent EU GDP and almost one fourth (23.26 percent) of total population in 2010: Austria, Germany, Greece and the Netherlands.

Abolition, in line with Stuart Mill (1870) and the United Nations Universal Declaration of Human Rights (1948), advocates that sexual exploitation should be extinct as well as non-coercive sex trade. Pimps and brothels managers should be prosecuted, but not the prostitutes themselves. This policy regime applies to the remaining $20 \mathrm{Member}$ States ${ }^{1}$ that account for 69.1 percent EU GDP and 71.2 percent of total population in 2010.

There are two distinct but related approaches. One addresses the issue of prostitution as legal sex work, a market economic activity that deserves thorough analysis in terms of supply and demand. The other one addresses the issue of coercive prostitution in terms of victims of sexual exploitation or forced labour; the emphasis is upon illegal trafficking within a given country as well as cross-border migration, which is used as an approximation in order to estimate overall prostitution including both coercive and non-coercive sex work that actually blurs such distinction.

The paper is structured as follows. Section two reviews the economics literature with respect to sex work and sexual exploitation. Section three records the data sources on the demand-side and the supply-side in order to assess how large is the sex market. Section four addresses five estimates on the supply-side: HIV prevalence amongst female sex workers provides Estimates $1 \mathrm{~A}$ and $1 \mathrm{~B}$; we calculate Estimates $2 \mathrm{~A}$ and $2 \mathrm{~B}$

${ }^{1}$ Neoabolitionism emphasizes the prosecution of customers in Sweden and France. 
from data collected by international NGOs; we design Estimate 3 from victims of sexual exploitation trafficking according to Eurostat and the UNODC in 2010. Section five designs an OLS model to test the five Estimates for prostitution according to GDP per capita, legislation, supply-side and demand-side variables. Section six checks Estimates of prostitution as regards National Accounts adjustment for illegal production as well as from consumption expenditure. Conclusion discusses what might be the most likely Estimates according to adjusted National Accounts figures for 2010.

\section{Literature review on prostitution}

Two strands in the recent economics literature address prostitution and few papers deal with the empirical issue. One explores various theoretical models based upon and extending the general assumption of rational choice behaviour from sex workers. The other one focuses on victims of sexual exploitation.

Edlund and Korn (2002) design the first formal model of occupational choice involving voluntary prostitution according to rational choice. They state the prostitution puzzle as "low-skilled, labor intensive, female, and well paid" and explain that sex workers draw a compensating differential due to the foregone opportunity to "sell" their fertility in the marriage market.

Della Giusta et al. (2009) extend the standard model of rational action, including social interactions and social sanctions. They focus upon stigma as a loss of reputation, which affects social standing for both clients and sex workers. Attitudes towards the exchange of paid sex shape the dynamics of demand and supply and the resulting markets.

Farmer and Horowitz (2013) intermediaries into a theoretical analysis of market structure with heterogeneous buyers and sellers as well as information asymmetry. The market is segmented into separating equilibria and intermediaries affect the distribution of surplus. If brothels are authorized, they are likely to reduce information asymmetry and costs as well as promote economies of scale and quality.

Lee and Persson (2015) model a semi-coerced market with voluntary prostitutes and trafficking, investigating whether prostitution laws can reach the socially optimal outcome that would arise in a decriminalized market free from trafficking. No regulatory regime currently used achieves this goal, but a combination of the "Dutch" regulatory and the "Swedish" neo-abolitionist regimes would.

Immordino and Flaviano Russo (2014) set up an equilibrium model of prostitution wherein potential clients and sex workers simultaneously interact under three different legal regimes and the harm associated to each. An application to Italy documents a tradeoff between equilibrium and social optimum. Prohibition is more effective at decreasing the total quantity of prostitution services than regulation and laissez-faire regimes. Regulation is more effective than prohibition in alleviating the harm associated with prostitution.

Three papers address the issue of sexual exploitation trafficking. 
Akee et al. (2011) use a game-theoretic model to explore the human trafficking market and estimate a gravity model of trafficking upon a sample of 190 countries. They find that domestic and foreign enforcement do mutually reinforce one another, due to mobility, there is partial bargaining power of traffickers and buyers, and demand.is inelastic. Legal prostitution exerts no effect on trafficking in a two-country pair crosssectional sample (country source to host country); whereas there is a negative effect when using instrumental variables.

Cho et al (2013) address the effect of legalising prostitution upon a global dataset of 150 countries. It will increase demand as well as some potential sex workers (or their pimps) to enter the market. Supply might decline due to tax collection. However, prostitutes unwilling to comply with tax payment, can operate illegally. The legalisation of prostitution has two opposite effects on the incidence of trafficking, a substitution effect away from trafficking and a scale effect increasing trafficking. Hence, the overall effect is theoretically indeterminate and becomes an empirical issue.

Jakobsson and Kotsadam (2013), using a cross-sectional dataset of 31 European countries from the ILO and UNODC, find a positive effect of legal prostitution on trafficking in. Sexual exploitation trafficking of women is least prevalent in countries where prostitution is illegal, most prevalent in countries where prostitution is legal, and in between in those countries where prostitution is legal but procuring illegal. Case studies of Norway and Sweden, which prosecute buying sex, support the possibility of a causal link from harsher prostitution laws to reduced trafficking.

\section{How large is the sex market in the EU on the demand side?}

There are various criteria to gauge the market for sexual services depending on their prices, premises and working schedules. Prostitution encapsulates three broad distinct segments: the upper tier or luxury prostitution (escorts and call girls); the intermediate category includes the brothels, bars, clubs, massage parlours and other indoor prostitution; outdoor or street prostitution is the lower tier. Furthermore, some students and housewives participate on a part time basis in addition to full time professionals. It is common knowledge that data on prostitution are scant and expert's calculations are 'guesstimates'. Hence, with few exceptions, we assume that prostitution is an equivalent full-time activity, the magnitude of which we measure, thanks to qualitative and quantitative surveys issued from primary as well as secondary sources.

\section{Box 1. Prices for sex trade and earnings premia}

We compiled piecemeal data from 21 EU countries (Czech Rep., France, Luxembourg, Malta, Slovakia, Slovenia and Sweden are missing) from Havocscope Black Market (www.havocscope.com). Prices for street prostitution range from $€ 13$ up to $€ 63$ and $€ 27$ is the average price for twelve countries. Regarding brothels, the range is $€ 30-67$, with an average price of $€ 45$ (eight countries) that stands over one and a half times higher than street prostitution. Escort girls would charge from $€ 37$ up to $€ 225$ in five countries, with an average price of $€ 125$ that stands more than four and a half times as high as that of street prostitution. Weighing outdoor (0.4) and indoor (0.6) prostitution, average price would amount to $€ 38$. 
Assuming that these are (net) hourly prices and that prostitutes earn half of the average price, whereas the other half is the pimp's cut, we may compare with median gross hourly earnings for EU-27 employees in 2010 (Eurostat earn_ses_pub2i), namely $€ 11.8$. There is a premium as for earnings from street prostitution (€13.5), brothels (€22.5) and escorts (€ 62.5).

All studies agree that demand for prostitution comes from men. The issue remains controversial as regards male behaviour. In line with Stuart Mill (1870), abolitionists contend that demand should -and actually can be curbed, whereas Cho et al (2013) assume that demand is inelastic (Malthus, 1798).

Table 1. Proportion of men reporting having commercial sex in the past 12 months

\begin{tabular}{|c|c|c|c|}
\hline Country & Year & Prevalence of clients of Female Sex Workers & Source \\
\hline France & 1992 & $1.1 \%$ & Natsal \\
\hline France & 1998 & $0.7 \%$ & NEM \\
\hline Germany (West) & 1990 & $4.8 \%$ & Natsal \\
\hline Germany & 1998 & $0.0 \%$ & NEM \\
\hline Greece & 1998 & $5.3 \%$ & NEM \\
\hline Italy & 1992 & $2.0 \%$ & Natsal \\
\hline Italy & 1998 & $1.7 \%$ & NEM \\
\hline Netherlands & 1989 & $2.8 \%$ & Natsal \\
\hline Portugal & 1991 & $5.4 \%$ & Natsal \\
\hline Portugal & 1999 & $2.4 \%$ & NEM \\
\hline Spain & 1990 & $11.0 \%$ & Natsal \\
\hline UK & 1990 & $2.0 \%$ & Natsal \\
\hline UK & 1998 & $1.0 \%$ & NEM \\
\hline
\end{tabular}

Source: Carael et al (2006)

National surveys on sexual behaviour in Europe developed between 1990 and 2000 (Hubert et al, 1998; Johnson et al, 2001) and addressed the proportion of men reporting having commercial sex in the past 12 months (Table1). 
In the early nineties, National surveys on sexual behaviour (Natsal) were conducted in seven Member States upon a sample including only 18-49 years old age group. There are large discrepancies in reported contact with a sex worker: 1.1 per cent in France and 11.0 per cent in Spain. The median value is 4.95 per cent, with a mean of 4.1 per cent.

In the late nineties, surveys based upon the EU New Encounter Module (NEM) upon a sample of all adult age groups cover only five Member States and provide much smaller estimates: The median value is 2.22 per cent, with a mean of 2.65 per cent.

It is worth noticing there is a bias in the early 1990s surveys due to age concentration and small sample size for some countries; hence, one cannot conclude that demand is diminishing.

\section{How large is the sex market in the EU on the supply side?}

\subsection{Estimates of female sex workers from HIV prevalence}

We assume that sex workers are overwhelmingly females (90 per cent); hence, we do not address male and transgender prostitution that nevertheless does exist.

Table 2. Estimates of female sex workers from HIV prevalence in the 2000s

\begin{tabular}{|l|c|l|l|l|l|}
\hline Country & $\begin{array}{c}\text { Female +15 } \\
\text { years old } \\
(2011)\end{array}$ & $\begin{array}{l}\text { Female sex } \\
\text { workers as a } \\
\text { \% of females } \\
+15 \text { years old } \\
\text { (late 2000s) }\end{array}$ & $\begin{array}{l}\text { Estimate 1A } \\
\text { Number of } \\
\text { female sex } \\
\text { workers } \\
\text { (late 2000s) }\end{array}$ & $\begin{array}{l}\text { Female sex } \\
\text { workers as a \% } \\
\text { of females + } \\
\text { 15 years old } \\
\text { (early 2000s) }\end{array}$ & $\begin{array}{l}\text { Number of } \\
\text { female sex } \\
\text { workers } \\
\text { (early 2000s) }\end{array}$ \\
\hline Austria & 2831855 & 0.5 & 14,16 & $1.0 \%$ & 26,944 \\
\hline Belgium & 3599767 & 0.2 & 7,2 & $0.4 \%$ & 13,545 \\
\hline Bulgaria & 2500139 & 0.3 & 7,5 & $0.6 \%$ & 15,988 \\
\hline Croatia & 1438394 & 0.2 & 2,877 & $0.5 \%$ & 7,231 \\
\hline Cyprus & 304272 & Na $(0.3)^{*}$ & 0,913 & Na $(0.5 \%)^{*}$ & 1,521 \\
\hline Czech Rep & 3622042 & 0.2 & 7,244 & $0.4 \%$ & 14,409 \\
\hline Denmark & 1801669 & 0.2 & 3,603 & $0.4 \%$ & 7,028 \\
\hline Estonia & 455730 & 0.5 & 2,278 & $1.1 \%$ & 5,254 \\
\hline Finland & 1753497 & 0.1 & 1,753 & $0.3 \%$ & 5,137 \\
\hline
\end{tabular}




\begin{tabular}{|c|c|c|c|c|c|}
\hline France & 20608570 & 0.1 & 20,608 & $0.2 \%$ & 38,506 \\
\hline Germany & 26666646 & 0.7 & 186,666 & $1.4 \%$ & 385,266 \\
\hline Greece & 3676071 & 0.2 & 7,352 & $0.4 \%$ & 14,681 \\
\hline Hungary & 3472528 & 0.3 & 10,417 & $0.6 \%$ & 21,222 \\
\hline Ireland & 1539528 & $\mathrm{Na}(0.3)^{*}$ & 4,818 & $\mathrm{Na}(0.5 \%)^{*}$ & 7,697 \\
\hline Italy & 19567814 & 0.2 & 39,136 & 0.4 & 7,7283 \\
\hline Latvia & 724906 & 0.7 & 5,074 & $1.5 \%$ & 12,143 \\
\hline Lithuania & 1063308 & 0.4 & 4,253 & $0.7 \%$ & 8,251 \\
\hline Luxembourg & 172648 & 0.2 & 0,345 & $0.4 \%$ & 0,570 \\
\hline Malta & 141449 & $\mathrm{Na}(0.3)^{*}$ & 0,424 & $\mathrm{Na}(0.5 \%)^{*}$ & 0,707 \\
\hline Netherlands & 5538148 & 0.3 & 16,614 & $0.6 \%$ & 31,833 \\
\hline Poland & 13580266 & 0.3 & 40,741 & $0.6 \%$ & 78,751 \\
\hline Portugal & 3582038 & $\mathrm{Na}(0.3)^{*}$ & 10,746 & $\mathrm{Na}(0.5 \%)^{*}$ & 17,910 \\
\hline Romania & 6866235 & 0.4 & 27,465 & $0.8 \%$ & 59,305 \\
\hline Slovakia & 1938685 & 0.2 & 3,877 & $0.4 \%$ & 7,658 \\
\hline Slovenia & 689707 & 0.7 & 4,828 & $1.4 \%$ & 9,671 \\
\hline Spain & 15637867 & 0.3 & 46,914 & $\mathrm{Na}(0.5 \%)^{*}$ & 78,189 \\
\hline Sweden & 3006611 & 0.05 & 1,503 & $0.1 \%$ & 2,799 \\
\hline UK & 20882796 & 0.3 & 62,648 & $0.5 \%$ & 96,174 \\
\hline$E U-28$ & 168316690 & $0.3^{*}$ & 541,957 & $0.5 \% *$ & 976,118 \\
\hline
\end{tabular}

Source: Prüss-Ustün et al (2013); Vandepitte et al (2006) Na : Not available. * Median value

In Table 2, we estimate the number of female sex workers using two series of data from HIV prevalence collected from the World Health Organisation. In the first series, data for 23 EU countries relate either to 2000 or 2004 (Vandepitte et al, 2006); we 
adjusted for missing data with the median value of HIV prevalence in the EU (0.5 per cent): Estimate 1B of the number of female sex workers is slightly below one million. In the second series, data for $24 \mathrm{EU}$ countries relate to mid and late 2000s (PrüssUstün et al, 2013); we adjusted for missing data with the median value of HIV prevalence in the EU ( 0.3 per cent), Estimate $1 \mathrm{~A}$ of the number of female sex workers shrinks to slightly over half a million.

Comparing these two series, one should not conclude that the magnitude of prostitution has declined, which would run opposite to the trend in demand. It is quite unlikely a serious drop in HIV prevalence occurred during so short a period that would only be due to safer sex practices, an assumption that is not documented. At last, there is no reason to assume that epidemic recording has deteriorated over time. We have yet no strong clue to decide whether Estimate $1 \mathrm{~A}$ understates the magnitude of sex work, although Prüss-Ustün et al (2013) acknowledge the survey coverage for female sex workers was adjusted for injection drug use and makes it a conservative estimation; conversely, Estimate 1B may overstate the magnitude.

\subsection{Estimates from NGOs}

An international NGO defending sex workers (TAMPEP, 2010) sent 600 standardised questionnaires to key organisations among its network in 2008, mostly NGOs and Health Services in direct contact with sex workers. It collected 380 responses that helped building up reports for 23 EU countries; Croatia, Cyprus, Ireland, Malta and Sweden are missing (See Table 2). Some answers regarding earnings suggest that the questions were misunderstood and estimates were not checked. Almost two thirds of sex workers in Europe work indoor. Twelve EU countries wherein the share of migrants among sex workers is above 50 per cent are net importers. Conversely, ten EU countries wherein the share of nationals among sex workers is above 50 per cent are most likely to be exporters. One third of migrants came from EU countries; Romania and Bulgaria were most mentioned countries of origin. The distribution of sex workers is respectively 30 per cent and almost 70 per cent for nationals and migrants. Migrants are highly mobile and more vulnerable as regards working conditions and risks (including HIV as well as deportation); two thirds are prone to be exploited by third party (pimps and brothel managers), whereas the share is one third as for nationals. Hence, most sex workers especially migrants is trapped in forced labour.

In order to fill in the vacuum for the five missing countries from TAMPEP and do justice to other estimates, we collected the figures from the abolitionist Scelles foundation (Charpenel, 2013) and the UNODC (2014) that are included in Table 3.

These figures come from miscellaneous sources (NGOs, the police, etc.) and no information is available as regards coverage and time period for data collection. We compiled all estimates whatever sources for $26 \mathrm{EU}$ countries and completed the missing data for Cyprus and Malta with the median value of the sample. We designed Estimate $2 \mathrm{~A}$ as the highest of the lowest figures for EU-28 that amounts to 748,000 
prostitutes, whereas Estimate 2B from the lowest of the highest figures for EU-28, amounts to $1,310,000$ prostitutes.

Table 3. Sex workers in the EU circa 2010: Estimates 2A and 2B from NGOs

\begin{tabular}{|c|c|c|c|c|c|c|}
\hline \multirow{3}{*}{$\begin{array}{l}\text { Country } \\
\text { Austria }\end{array}$} & Outdoor & Migrants & \multicolumn{2}{|c|}{ Number of prostitutes } & \multirow{3}{*}{$\begin{array}{l}\text { Estimate 2A: } \\
\text { Highest of } \\
\text { the lowest } \\
10,000\end{array}$} & \multirow{3}{*}{\begin{tabular}{|}
$\begin{array}{l}\text { Estimate 2B } \\
\text { Lowest of } \\
\text { the highest }\end{array}$ \\
27,000
\end{tabular}} \\
\hline & \multicolumn{3}{|c|}{ (TAMPEP) } & (Charpenel) & & \\
\hline & $15 \%$ & $78 \%$ & $27,000-30,000$ & $5,500-10,000$ & & \\
\hline Belgium & $34 \%$ & $60 \%$ & $15,000-20,000$ & $10,000-15,000$ & 15,000 & 20,000 \\
\hline Bulgaria & $33 \%$ & $2 \%$ & $6,000-10,000$ & $8,000-10,000$ & 10,000 & 10,000 \\
\hline Croatia & & & & 6,700 & 6,700 & 6,700 \\
\hline Cyprus & & & & & 915 & 1,446 \\
\hline Czech Rep. & $19 \%$ & $41 \%$ & $10,000-13,000$ & $5,000-25,000$ & 13,000 & 25,000 \\
\hline Denmark & $25 \%$ & $65 \%$ & 5,560 & 5,500 & 5,500 & 5,500 \\
\hline Estonia & $2 \%$ & $5 \%$ & $1,000-1,200$ & 1,000 & 1,000 & 1,200 \\
\hline Finland & $10 \%$ & $69 \%$ & $5,000-6,000$ & $12,000-15,00$ & 6,000 & 15,000 \\
\hline France & $61 \%$ & $61 \%$ & $18,000-30,000$ & $18,000-20,000$ & 20,000 & 30,000 \\
\hline Germany & $13 \%$ & $65 \%$ & 400,000 & $150,000-400,000$ & 150,000 & 400,000 \\
\hline Greece & $60 \%$ & $73 \%$ & 10,000 & $1,200-20,000$ & 10,000 & 20,000 \\
\hline Hungary & $40 \%$ & $25 \%$ & $10,000-15,000$ & $8,000-10,000$ & 10,000 & 15,000 \\
\hline Ireland & & & & 1,000 & 1,000 & 1,000 \\
\hline Italy & $60 \%$ & $90 \%$ & 50,000 & $50,000-100,000$ & 50,000 & 100,000 \\
\hline Latvia & $40 \%$ & $12 \%$ & $2,000-3,000$ & $15,000-20,000$ & 3,000 & 20,000 \\
\hline Lithuania & $57 \%$ & $10 \%$ & $1,250-1,550$ & & 1,550 & 1,550 \\
\hline Luxembourg & $30 \%$ & $92 \%$ & 5,000 & & 5,000 & 5,000 \\
\hline
\end{tabular}




\begin{tabular}{|c|c|c|c|c|c|c|}
\hline Malta & & & & & 467 & 467 \\
\hline Netherlands & $11 \%$ & $60 \%$ & $10,000-15,000$ & $20,000-30,000$ & 15,000 & 30,000 \\
\hline Poland & $40 \%$ & $34 \%$ & 10,000 & 12,000 & 10,000 & 12,000 \\
\hline Portugal & $45 \%$ & $56 \%$ & 9,700 & 28,000 & 9,700 & 28,000 \\
\hline Romania & $64 \%$ & $2 \%$ & $2,500-3,800$ & $2,000-23,000$ & 3,800 & 23,000 \\
\hline Slovakia & $73 \%$ & $2 \%$ & 7,500 & & 7,500 & 7,500 \\
\hline Slovenia & $2 \%$ & $30 \%$ & $1,500-3,000$ & & 1,500 & 3,000 \\
\hline Spain & $46 \%$ & $90 \%$ & 6,000 & $300,000-400,000$ & 300,000 & 400,000 \\
\hline Sweden & & & & 1,500 & 1,500 & 1,500 \\
\hline UK & $23 \%$ & $41 \%$ & $58,000-80,000$ & $80,000-100,000$ & 80,000 & 80,000 \\
\hline$E U-28$ & & & $\begin{array}{l}693,000- \\
730,000\end{array}$ & $\begin{array}{c}740,400- \\
1,253,700\end{array}$ & 747,970 & $1,309,634$ \\
\hline
\end{tabular}

Source: Charpenel (2013), TAMPEP (2010), UNODC (2014) and own calculations

\subsection{Forced labour, sexual exploitation trafficking and prostitution}

The ILO (2012), Eurostat (2013a) and UNODC (2014) provide fragmented information on the patterns of prostitution and its magnitude in the EU. Data available across countries cover the characteristics of victims and trafficking routes. Their main limitation is that recording depends on judicial and police effectiveness. Databases do not collect necessarily from the same source: neither UNODC nor Eurostat collect primary sources, whereas the ILO uses both primary and secondary sources.

\subsubsection{Estimate of forced sexual labour trafficking from the ILO}

The ILO (2009) designed from experts a list of 67 indicators related to trafficking with respect to recruitment, working conditions and coercion. The subset of indicators for sexual exploitation encapsulates very bad working conditions (including excessive working time and hazardous work), low or no salary (including wage manipulation) and no compliance with labour regulations (including the absence of contract signed and social protection). It leaves room for non-coercive prostitution (including casual activity) that is not related to sexual exploitation.

The ILO (2012) computed a global estimate of forced labour for the 2002-2011 reference period from a capture-recapture investigation based on reported cases from 
different sources (research institutes, NGOs and the media). Forced sexual exploitation amounts to 270,000 female victims (98 per cent) and the average duration is less than 18 months for sexual exploitation turover. This Estimate $3 \mathrm{~A}$ does not gauge the magnitude of overall prostitution.

\subsubsection{A Eurostat-UNODC Estimate of sexual exploitation trafficking in the EU}

Eurostat (2013a) collected data on human beings trafficking over the period 20082010. It is acknowledged that the EU currently lacks reliable and comparable statistical information on trafficking in human beings. This is mainly due to the differences between the Member States in the criminal codes, in the reporting and monitoring systems as well as for the rates of reporting cases to the police, NGOs and other entities. In the year 2010, 24 EU Member States reported a total number of 9,528 identified and presumed victims of trafficking, whereas the total number of identified victims is 5,535. Data are broken down between other forms of forced labour and sexual exploitation, which amounts to the largest share of victims (62 per cent) that are predominantly female (96 per cent). Sexual exploitation includes all forms of forced prostitution whether indoor or outdoor. Most victims detected in EU Member States are citizens from Romania and Bulgaria. Suspected traffickers for sexual exploitation represent approximately 84 per cent of the total number of suspected traffickers over the three reference years.

\section{Box 2. The Palermo Protocol}

The United Nations Protocol to Prevent, Suppress and Punish Trafficking in Persons, Especially Women and Children, coined as the Palermo Protocol (2000) entered in force in 2003, setting the minimum standards for the elimination of trafficking of human beings in terms of prosecuting traffickers and supporting victims. The United Nations Office on Drugs and Crime (UNODC) is in charge of the implementation and records the victims (UNODC, 2014). The Palermo Protocol states that exploitation of prostitution and trafficking cannot be separated, albeit it does not apply to non-coercive prostitution. Tier 1 gathers the 17 EU Member States that fully comply with the minimum standards. The remaining $11 \mathrm{EU}$ Member States that do not fully comply belong to Tier 2, which gathers countries from all threeprostitution policy regimes. See Table 4.

UNODC (2014) provides some similar patterns for the period 2010-2012. Among the detected victims trafficked to EU countries, sexual exploitation is prevalent (66.25 per cent). focusing on economic gains involved in exploiting people, domestically or abroad. According to the gap with the country of origin, the richer the destination country, the higher the profits sexual exploitation can generate. The price of women depends on the expected profit and the perceived risk associated with carrying out the crime, as well as the demand for sex services in the destination country. In Central Europe and the Balkans, domestic trafficking accounts for about 80 per cent of the detected victims in accordance with previous findings (TAMPEP, 2010).

We compared and compiled data for victims of sexual exploitation in 2010 from Eurostat (2013a) and UNODC (2014). Table 5 reports the numbers of victims for 20 
EU countries. With regard to consistency, we first checked both series of data for the same 18 EU countries; the data do not match for Spain. We computed the missing data thanks to the average share of victims according to the UNODC series. At last, we completed the series for all 28 EU countries, using Eurostat series when available and UNODC otherwise. Large countries such as Italy and Poland did not provide data although they belong to the Tier 1 Palermo Protocol. We calculated the "Number of victims/100000" by dividing "Number of victims of sexual exploitation in 2010" (sixth column) per "Population in 100,000 in 2010" (second column).

In the EU-28, the average number of victims of sexual exploitation is over one (1.16) for a thousand hundred inhabitants in 2010. Bulgaria, Estonia, and Romania as well as Cyprus do not fully comply with the Palermo Protocol and stand above average; such is also the case for Slovenia that is compliant. Fully compliant countries from Western and Southern Europe such as Ireland, Luxembourg, the Netherlands and Spain also stand above average and France is pretty close to average.

Table 4. Victims of sexual exploitation and prevalence in the EU for year 2010

\begin{tabular}{|c|c|c|c|c|c|c|c|}
\hline & & & Sexual e & xploitation & ר. Number of & f victims & \\
\hline $\begin{array}{l}\text { EU } \\
\text { Member } \\
\text { States }\end{array}$ & $\begin{array}{l}\text { Population } \\
(100,000)\end{array}$ & $\begin{array}{l}\text { Palermo } \\
\text { Protocol } \\
\text { compliant }\end{array}$ & $\begin{array}{l}2010 \\
\text { (Eurostat) }\end{array}$ & $\begin{array}{l}\text { Average. } \\
\text { (UNODC) }\end{array}$ & $\begin{array}{l}2010 \\
\text { (Eurostat or } \\
\text { UNODC) }\end{array}$ & $\begin{array}{l}/ 100,000 \\
\text { inhabitants }\end{array}$ & $\begin{array}{l}\text { Prostitution } \\
\text { extrapolated } \\
(x 20 \times 7)\end{array}$ \\
\hline Austria & 83,751 & Tier 1 & & 49 & 49 & 0.585063 & 6,860 \\
\hline Belgium & 110,006 & Tier 1 & 43 & & 43 & 0.390886 & 6,020 \\
\hline Bulgaria & 73,694 & Tier 2 & 366 & 406 & 366 & 4.966462 & 51,240 \\
\hline Croatia & 42,898 & Tier 2 & 2 & 6 & 4 & 0.093243 & 560 \\
\hline Cyprus & 8,397 & Tier 2 & 24 & 24 & 24 & 2.85799 & 3,360 \\
\hline Czech Rep. & 104,867 & Tier 1 & 3 (15) & 36 & 45 & 0.429114 & 6,300 \\
\hline Denmark & 55,606 & Tier 1 & 50 & 70 & 50 & 0.899179 & 7,000 \\
\hline Estonia & 13,296 & Tier 2 & & 16 & 20 & 1.504144 & 2,800 \\
\hline Finland & 53,752 & Tier 1 & 26 & 20 & 26 & 0.483696 & 3,640 \\
\hline France & 649,787 & Tier 1 & 726 & 702 & 726 & 1.117289 & 101,640 \\
\hline
\end{tabular}




\begin{tabular}{|c|c|c|c|c|c|c|c|}
\hline Germany & 817,516 & Tier 1 & 610 & 419 & 610 & 0.746163 & 85,400 \\
\hline Greece & 111,233 & Tier 2 & & 69 & 71 & 0.638295 & 9,940 \\
\hline Hungary & 99,857 & Tier 2 & 5 & 68 & 48 & 0.480686 & 6,720 \\
\hline Ireland & 45,708 & Tier 1 & 56 & 44 & 56 & 1.225147 & 7,840 \\
\hline Italy & 593,646 & Tier 1 & & 61 & 57 & 0.096017 & 7,980 \\
\hline Latvia & 20,746 & Tier 2 & 4 & 4 & 4 & 0.192808 & 560 \\
\hline Lithuania & 30,525 & Tier 2 & & 15 & 13 & 0.425868 & 1,820 \\
\hline Luxembourg & 5,118 & Tier 1 & 6 & & 6 & 1.172241 & 840 \\
\hline Malta & 4,149 & Tier 2 & 4 & & 4 & 0.963881 & 560 \\
\hline Netherlands & 166,558 & Tier 1 & 749 & 900 & 749 & 4.496932 & 104,860 \\
\hline Poland & 380,622 & Tier 1 & & 169 & 169 & 0.444004 & 23,660 \\
\hline Portugal & 105,727 & Tier 2 & & 10 & 17 & 0.160791 & 2,380 \\
\hline Romania & 201,990 & Tier 2 & 482 & 520 & 482 & 2.38625 & 67,480 \\
\hline Slovakia & 53,924 & Tier 1 & 21 & 13 & 21 & 0.389434 & 2,940 \\
\hline Slovenia & 20,501 & Tier 1 & 30 & 22 & 30 & 1.46328 & 4,200 \\
\hline Spain & 466,671 & Tier 1 & 1605 & 207 & 1,605 & 3.439248 & 224,700 \\
\hline Sweden & 9,41557 & Tier 1 & 19 & 34 & 19 & 0.201793 & 2,660 \\
\hline UK & 630,225 & Tier 1 & 170 & 173 & 170 & 0.269745 & 23,800 \\
\hline EU-28 & $5,044,944$ & & 4,98 & 4,057 & 5,484 & 1.161416 & 767,760 \\
\hline
\end{tabular}

Source: our compilation from Eurostat (2013a) and UNODC (2014).

According to UNODC (2010) the detection ratio is one in 20 victims of sexual exploitation trafficking and one sex worker in seven would be a trafficking victim ${ }^{2}$. If we use these figures, there would be a flow 100,000 victims for sexual exploitation in the

2 The multiplier of 20 for every victim detected, comes from a pilot survey tested in Spain, Italy and Finland in the early 2000 s. The share of victims among sex workers remains unexplained. 
EU 28 in 2010 (5,000 recorded victims times 20) and over 750,000 sex workers. However, UNODC calculates a stock from a flow, ignoring how large is the flow that leaves the market (replacement) or just moves across countries. If net inflow increases, the stock of prostitutes may be rising over time and this should lower prices, unless there is an increase in demand.

We apply the multiplier (times 20 times seven) to the number of victims of sexual exploitation in each country and extrapolate the magnitude of prostitution (see last column in table): we come up with an overall figure of 767,760 prostitutes for EU-28, which is our Estimate 3B. Some results are obviously absurd as regards country distribution: for instance, Germany counts less prostitutes than the Netherlands albeit five times larger a population. Hence, one may be very skeptical as for the accuracy of such a proxy to gauge prostitution at country level (Savona and Stefanizzi, 2007).

\section{Testing the estimates of prostitution}

We test our five Estimates thanks to OLS regressions based on cross-section data for $28 \mathrm{EU}$ countries, referring to the year 2010. We test the following model:

$Y_{i}=\alpha+\beta_{1}$ Prostitution $_{i}+\beta_{2} X i+\beta_{3}$ Sub-regions $_{i}+\varepsilon_{i}$

$Y_{i}$ represents the various estimates for sex work in country $i$ : Estimates $1 \mathrm{~A}$ and $1 \mathrm{~B}$ from HIV prevalence, Estimates $2 \mathrm{~A}$ and 2B from NGOs and Estimate 3B from extrapolated number of victims of sexual exploitation. Prostitution ${ }_{i}$ is our dummy variable indicating whether prostitution is legal or not. $X$ is the vector of explanatory variables, Sub-

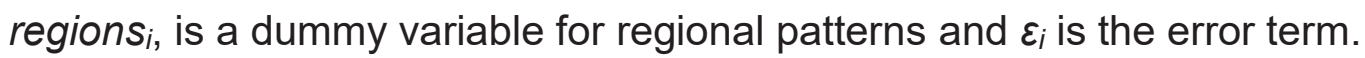

As for the variable Prostitution, we test both legal status for prostitution and for brothels in country $i$, by testing two dummy variables. First, whether prostitution is legal or not, being 1 in this case and 0 otherwise; second, whether or not third-party involvement (such as brothel manager or pimp) is legal, being 1 whenever brothels are legal and 0 otherwise. In both cases, the sign is expected to be positive.

We impute a number of explanatory country variables $X i^{3}$. GDP per capita takes into account the level of economic development that should influence the presence of a high number of sex workers. We include Total adult population to take into account the scale effect and we disentangle Adult female population on the supply-side from Adult male population on the demand-side. Focusing on the supply side, International female migrant stock per 100 thousand of population takes into account the importance of female migration in Western and Southern European countries; its sign is expected to be positive. Unemployment rate of females younger than 25 years tackles the assumption that the higher is unemployment, the more women may become sex workers; its sign is expected to be negative. Rate of female part-time workers tackles the assumption that prostitution may be a part-time job; its sign is expected to be

\footnotetext{
${ }^{3}$ In order to design the best models we run numerous regressions with several different variables such as the size of households, urbanisation, Internet use, earnings, educational attainment, status in employment and rate of activity for females. In addition, we used ordered probit models to check the ranking of countries, which changes according to estimates. All regressions and probit models as well as data sources are available upon request.
} 
negative. Control of corruption and Tier are, respectively, the indicators for countries government effectiveness and compliance with the Palermo protocol. Regarding Subregion $_{i}$, the divide between rich Western and Southern Europe and poorer countries from Eastern Europe (including the Balkans) is designed to catch the imbalance between net sex importers and net sex exporters.

As we use a cross-section dataset, we cannot control for unobserved country heterogeneity by including country fixed effects. The variables Legal prostitution and Legal brothels, Adult female population and Adult male population as well as Total adult population, Control of corruption and Tier were tested separately to avoid multicollinearity. All continuous variables were taken in logarithms. Eventually, we dropped Control of corruption and Tier and well as Sub-region, which were relevant only for Estimate 3 and proved insignificant.

We ranked Estimates according to correlation coefficient and the number of significant variables as follows: Estimates $1 \mathrm{~B}, 1 \mathrm{~A}, 2 \mathrm{~B}, 2 \mathrm{~A}$ and $3 \mathrm{~B}$. The results are recorded in Table 6 we comment hereafter.

GDP per capita is only significant but negative in Estimates $1 \mathrm{~A}$ and $1 \mathrm{~B}$, which may run against the intuition that higher GDP should attract more prostitutes (especially migrants).

On the supply-side, Adult female population (aged 15-64) is always very significant ( $p$ value is 0.1 ) and positive in all Estimates, making sure that prostitutes are women.

Legal brothels is significant in Estimates $1 \mathrm{~A}$ and $1 \mathrm{~B}$ ( $\mathrm{p}$-value is 0.1 ) as well as in Estimates $2 A$ and $3 B$ ( $p$-value is 0.05 ); it proves always positive, in line with the results of existing literature (Cho et al, 2013; Jakobsson and Kotsadam, 2013).

International female migrant stock per 100,000 of population is significant in Estimates $1 \mathrm{~A}$ and $1 \mathrm{~B}$ ( $\mathrm{p}$-value is 0.01 ); it is positive in all Estimates save Estimate 3B.

Unemployment rate of females below 25 is very significant ( $p$-value is 0.01 ) in Estimates $2 \mathrm{~A}$ and $2 \mathrm{~B}$; it proves negative in all Estimates, suggesting that unemployment does not drive prostitution.

Rate of female part-time workers is weakly significant ( $p$ value is 0.01 ) or insignificant and proves negative in all Estimates (save $3 \mathrm{~B}$ ), suggesting that prostitution is a fulltime job.

On the demand-side, Adult male population (aged 15-64) is always very significant ( $p$ value is 0.01 ) and positive in all Estimates, making sure that customers are men.

As regards the scale effect, Total adult population is always very significant ( $p$-value is 0.01) and positive in all Estimates, in line with the results of Cho et al (2013).

\section{Table 5. Testing the estimates with the OLS models}




\begin{tabular}{|c|c|c|c|c|c|}
\hline Best models & $\begin{array}{c}\text { Estimate } \\
1 \mathrm{~A}\end{array}$ & $\begin{array}{c}\text { Estimate } \\
1 \mathrm{~B}\end{array}$ & $\begin{array}{c}\text { Estimate } \\
\text { 2B }\end{array}$ & $\begin{array}{c}\text { Estimate } \\
2 \mathrm{~A}\end{array}$ & $\begin{array}{c}\text { Estimate } \\
\text { 3B }\end{array}$ \\
\hline \multicolumn{6}{|l|}{ Variables } \\
\hline LnGDP per capita & $-0.847^{* * *}$ & $-0.973^{* * *}$ & 0.336 & 0.054 & -0.115 \\
\hline LnAdultfemalepopulation & $1.027^{* * *}$ & & & & $0.572^{* * *}$ \\
\hline Legal brothels & $0.568^{* *}$ & $0.575^{* * *}$ & 0.725 & $1.095^{* *}$ & $1.327^{* *}$ \\
\hline Leg prostit. & & & $0.742^{* *}$ & $0.836^{*}$ & 0.671 \\
\hline LnFemale migrant stock & $0.415^{* * *}$ & $0.419 * * *$ & 0.216 & 0.234 & $-0.635^{*}$ \\
\hline Unemployment females & $-0.039 * * *$ & $-0.036^{* * *}$ & -0.000 & -0.010 & \\
\hline Part-time female workers & -0.006 & -0.004 & $-0.024^{*}$ & $-0.025^{*}$ & $0.021^{*}$ \\
\hline LnAdultMalepopulation & & $1.020^{* * *}$ & $0.884^{* * *}$ & $0.907^{* * *}$ & \\
\hline \multicolumn{6}{|l|}{ LnTotalpopulation } \\
\hline Constant & $11.360^{* * *}$ & $13.132^{* * *}$ & 0.716 & 3.856 & $12.191^{* * *}$ \\
\hline $\mathrm{N}$ & 28 & 28 & 28 & 28 & 28 \\
\hline $\mathrm{R}^{2}$ & 0.930 & 0.931 & 0.816 & 0.792 & 0.747 \\
\hline
\end{tabular}

Source: our compilation Robust standard errors are omitted. ${ }^{* * *} p<0.01,{ }^{* *} p<0.05,{ }^{*} p<0.1$

\section{Prostitution and National Accounts adjustment}

\subsection{The Non Observed Economy (NOE) and illegal prostitution}

In search for exhaustiveness dating back to SNA 1993 and ESA 1995 (Eurostat, 2013b), Eurostat (2005) developed a new typology of the Non Observed Economy (NOE) including seven components (N1 to N7), which can be aggregated for purpose of parsimony into four or five categories of unrecorded activities (Gyomai and Van de Ven, 2014). The focus is upon illegal production (N2), which gathers all prohibited activities that are neither registered nor licensed and it encapsulates illegal prostitution as well as trafficking drug and smuggled or regulated goods (tobacco, alcohol, firearms, etc.).

By September 2014, all Member States adjusted their National Accounts to ESA 2010 as for data used to estimate European indicators, in order to ensure comparability. In this connection, member States were requested to compile illegal production (N2). The 
core issue is not that the inclusion of illegal production in the GDP count is morally unacceptable, but that calculating the illegal economy in itself is prone to inaccuracies due to coverage. Table 6 records the figures for $\mathrm{N} 2$ as well as the share of prostitution from the supply side and the demand side.

Table 6. Illegal production and prostitution contributing to GDP

\begin{tabular}{|c|c|c|c|c|c|c|}
\hline \multirow{3}{*}{$\begin{array}{l}\text { EU Member } \\
\text { States }\end{array}$} & \multirow{3}{*}{$\begin{array}{l}2010 \text { GDP } \\
\text { (€ billion) }\end{array}$} & \multirow{3}{*}{$\begin{array}{l}\text { N2 as a \% } \\
\text { of GDP }\end{array}$} & \multicolumn{4}{|c|}{ Prostitution from } \\
\hline & & & \multicolumn{2}{|c|}{ from the supply-side } & \multicolumn{2}{|c|}{ from the demand-side } \\
\hline & & & As a $\%$ of GDP & $€$ million & As a $\%$ of GDP & $€$ million \\
\hline Austria & 284 & $0.16 \%$ & $0.08 \%$ & 225 & $0.179 \%$ & 508.5 \\
\hline Belgium & 353 & $0.37 \%$ & $0.09 \%$ & 317.7 & $\mathrm{Nc}^{*}$ & Nc \\
\hline Bulgaria & 36 & $0.21 \%$ & $0.09 \%$ & 32.4 & $0.044 \%$ & 16.0 \\
\hline Croatia & 46 & $0.7 \%$ & $0.27 \%$ & 124.2 & Nc & Nc \\
\hline Cyprus & 17 & $1.09 \%$ & $0.31 \%$ & 52.7 & $0.33 \%$ & 56.2 \\
\hline Czech Rep. & 145 & $0.53 \%$ & $0.09 \%$ & 130.5 & $0.177 \%$ & 257.9 \\
\hline Denmark & 234 & $0.14 \%$ & $0.05 \%$ & 11.7 & Nc & $\mathrm{Nc}$ \\
\hline Estonia & 15 & $0.52 \%$ & $0.03 \%$ & 4.1 & $0.027 \%$ & 4.1 \\
\hline Finland & 180 & $0.1 \%$ & $0.03 \%$ & 54 & $0.053 \%$ & 96.0 \\
\hline France & 1,933 & $\begin{array}{r}\mathrm{Nc} \\
(0.21 \%)\end{array}$ & $\begin{array}{l}\mathrm{Nc} \\
(0.11 \%)\end{array}$ & $\begin{array}{r}\mathrm{Nc} \\
(2,170)\end{array}$ & $\begin{array}{l}\mathrm{Nc} \\
(0.14 \%)\end{array}$ & $\begin{array}{r}\mathrm{Nc} \\
(2,712.5)\end{array}$ \\
\hline Germany & 2,499 & $\begin{array}{r}0.1 \% \\
(0.23 \%)\end{array}$ & $\begin{array}{l}\mathrm{Nc} \\
(0.13 \%)^{2}\end{array}$ & $\begin{array}{r}\mathrm{Nc} \\
(3,248.7)\end{array}$ & Nc & Nc \\
\hline Greece & 230 & $\mathrm{Na}$ & $\mathrm{Na}^{* *}$ & $\mathrm{Na}$ & $0.19 \%$ & 437.0 \\
\hline Hungary & 98 & $0.85 \%$ & $0,49 \%$ & 480.2 & $0.641 \%$ & 628.6 \\
\hline Ireland & 156 & $0.73 \%$ & $0.036 \%$ & 56.16 & $0.038 \%$ & 59.5 \\
\hline Italy & 1,549 & $1 \%$ & $0.22 \%$ & 340.8 & Nc & $\mathrm{Nc}$ \\
\hline
\end{tabular}




\begin{tabular}{|c|c|c|c|c|c|c|}
\hline Latvia & 18 & $0.9 \%$ & $0.088 \%$ & 15.84 & $0.103 \%$ & 18.6 \\
\hline Lithuania & 27 & $\mathrm{Na}$ & $\mathrm{Na}$ & $\mathrm{Na}$ & $0.107 \%$ & 29 \\
\hline Luxembourg & 42 & $0.23 \%$ & $0.21 \%$ & 88.2 & $0.192 \%$ & 81 \\
\hline Malta & 6 & $0.3 \%$ & $0.14 \%$ & 9 & Nc & $\mathrm{Nc}$ \\
\hline Netherlands & 591 & $0.38 \%$ & $0.085 \%$ & 502.35 & $0.192 \%$ & 1139 \\
\hline Poland & 354 & $0.81 \%$ & $0.21 \%$ & 74.34 & $\mathrm{Nc}$ & $\mathrm{Nc}$ \\
\hline Portugal & 173 & $0.35 \%$ & $0.29 \%$ & 501.7 & $0.367 \%$ & 635.4 \\
\hline Romania & 122 & $0.46 \%$ & $0.06 \%$ & 73.2 & $0.071 \%$ & 86.7 \\
\hline Slovakia & 66 & $\mathrm{Na}$ & $\mathrm{Na}$ & $\mathrm{Na}$ & $0.074 \%$ & 49 \\
\hline Slovenia & 36 & $0,36 \%$ & $0.13 \%$ & 46.8 & $0.225 \%$ & 81.3 \\
\hline Spain & 1,063 & $0.87 \%$ & $0.35 \%$ & $3,720.5$ & Nc & $\mathrm{Nc}$ \\
\hline Sweden & 347 & $0,14 \%$ & $0.017 \%$ & 58.99 & $0.017 \%$ & 58.8 \\
\hline UK & 1,697 & $0.58 \%$ & $0.35 \%$ & $5,939.5$ & $0.383 \%$ & $6,504.7$ \\
\hline EU-28 & 12,314 & $\begin{array}{c}0.491 \% \\
€ 60.457,3\end{array}$ & $\begin{array}{c}0.173 \% \\
\text { (25 countries) }\end{array}$ & $€ 21,336$ & $\begin{array}{c}0.178 \% \\
\text { (20 countries) }\end{array}$ & $€ 21,857.35$ \\
\hline
\end{tabular}

Source: Brennan (2014), Casey (2014), Eurostat, FSO (2014), INE (2014), NAI (2014), Walton (2014). We checked figures with most the National Accounts division of EU-28 Statistics Offices

* Not compiled. ${ }^{* *}$ Not available

As for the revision of National Accounts, N2 coverage is focused on narcotics, prostitution and smuggling alcohol and tobacco. In some countries it may extend to piracy and illegal gambling. On the one hand, an abolitionist country such as France is reluctant to include prostitution in the GDP, arguing on moral grounds that it is not a voluntary exchange, although prostitution is already included to some extent. On the other hand, Germany wherein prostitution is regulated does not bother to include illegal prostitution, arguing that sex work is legal, although Cho et al (2013) point out that the number of illegal sex workers is significant. 
According to Dunn et al. (2014), upwards adjustment amounts to 0.4 per cent of EU-28 GDP, which may be a proxy for N2, whereas it is only 0.2 percent for EU GDP as for OECD countries (Van de Ven, 2015).

We compiled estimates for $\mathrm{N} 2$ and for prostitution from the supply side as of $23 \mathrm{EU}$ Member States. Coverage for prostitution from the demand side is recorded in Eurostat nama files as CP122 in the households' final consumption expenditure by consumption purpose (COICOP) for 19 EU countries in 2010. We included data for Germany from Kazemier and Rensam (2015) and we used adjusted data from Prostcost (2015) as for France. We calculated that N2 could amount to 0.49 percent of EU-28 GDP in 2010. Prostitution from the supply side as of 25 EU Member States - a 76.7 per cent share of EU-28 GDP in 2010 - would account for a 0.173 per cent mean. From the demand side as for 20 EU countries in 2010, which is a 50.3 per cent share of EU-28 GDP, prostitution could amount to a 0.178 per cent mean.

\subsection{Back to supply and demand for assessing estimates}

We inspire from Kazemier et al (2013) to estimate prostitution as a whole, in as much as there are no available country data to compile the various segments of prostitution whether indoor or outdoor.

The turnover of the prostitution industry $(P)$ or receipt is the product of the number of prostitutes $(s w)$, the number of customers per prostitute (cust) and the average price per client $(p)$ :

$P=s w \times$ cust $\times p$

Turnover encapsulates domestic consumption $(C)$ and exports $(E)$, sexual services to customers from abroad:

$P=C+E$

The value added (VA) of the prostitution industry is the sum of the domestic consumption $(C)$ and exports minus imports $(M)$ minus intermediate consumption $(I C)$. Imports are the sexual services provided by foreign prostitutes resident in the country plus the consumption of sexual services brought abroad by residents. Intermediate consumption are the expenses of the prostitutes themselves (clothing, condoms and travel expenses) we assume to be 20 percent of turnover:

$V A=C+E-M-I C$

Gross earnings of the prostitutes is the turnover or receipt minus intermediate consumption, namely the value added (VA). Net earnings or income $(N I)$ is gross earnings minus the share of the managers or pimps (the rent, rooms and brothels). We assume that prostitutes pay half the value added $(V A)$ to the managers or pimps ${ }^{4}$ :

\footnotetext{
${ }^{4}$ We assume that all prostitutes are subjected to pimps, in as much as we ignore the share of non-coerced prostitution, which might be one third on average throughout the EU (TAMPEP, 2010). Of, course, net earnings could be lower if pimps retain a larger share of gains: Kara (2011) and the ILO (2012) suggest it is 70 per cent, which would include Intermediate Consumption.
} 
$N I=(0.5) V A$

Using the 0.173 per cent mean share of prostitution in GDP, overall share in EU-28 GDP would amount to $€ 21,336.58$ million. Gross sales turnover (including intermediate consumption) would then reach $€ 21,857.35$ million as of a 0.178 per cent mean share of prostitution in GDP.

We assume that the average price per client is $€ 38$ (See Box 1) and the average number of clients (or sex transactions) per prostitute is within the range of 1,040-1,300 over 260 working days throughout the year ${ }^{5}$.

Hence, we divide Gross sales turnover (€21,857.35 million) with 1,040-1,300 clients that pay $€ 38$ and we come up with a range of $442,456-553,070$ prostitutes, a figure that would match with Estimate 1A $(542,000)$.

We assume that the pimp retains 50 per cent of total earnings (TAMPEP, 2010; Kazemier et al, 2013). Each of the 542,000 prostitutes would get average net earnings per annum up to half $€ 40,237$ ( $€ 20,163$ ) per year and $€ 1,680$ per month.

In as much there are 748,000 prostitutes (Estimate $3 \mathrm{~A}$ ), each one would get average net earnings of $€ 14,610$ per annum and $€ 1,217.5$ per month. In both cases, net earnings are above minimum wages and average annual earnings for all 10 countries of Eastern and Central Europe as well as for Cyprus, Malta and Portugal (Eurostat_earnings); hence, there is a premium for prostitution as well as for migration.

On the demand side, the adult male EU population is 168 million. Dividing the $€$ $21,857.35$ million total expenditure customers spend on prostitution for an average price of $€ 38$, we come up with 575.193 million sexual services or clients. A crude assumption would be that a 6.6 per cent share of the adult male EU population (168 million) pays for sex at least once a week, a monthly expenditure of $€ 152$. Indeed, the share of adult male customers seems quite large, according to the figures from COICOP and surveys on sexual behaviour.

\section{Conclusion}

Data sources on prostitution are scant and rather inconsistent, especially as regards country distribution. To our best knowledge, the five EU-28 estimates we have compiled are the first ones in the economic literature on prostitution. Our sample is small (28 countries) albeit consistent because EU membership is binding with respect to budget issues and the requested harmonisation of National Accounts. Moreover, the EU is an open area for both labour and capital mobility, which makes cross-border trafficking easy. Recalling that the share of countries wherein brothels are legal is close to one fourth of total EU-28 population, our main finding for all models is that the regulation of

\footnotetext{
${ }^{5}$ As for the UK, figures prove controversial. Abramsky \& Drew (2014) estimate the number of clients per prostitute as four to six a day $(20,25$ and 30 per week), whereas Kara (2011) suggests eight to ten sex encounters a day in brothel and street prostitution. Assumptions do not match either across countries: Kazemier et al (2013) assume that prostitutes work 40 weeks a year in the Netherlands, whereas Kara (2011) assumes 52 weeks a year in the UK.
} 
legal brothels positively correlates with four Estimates; our results are in line with those of the existing literature.

We also suggest that there is a premium for prostitution, despite some mixed evidence that the upper end segment of the prostitution market may pull prices; conversely, the lower end may be far less profitable. We bring in value added, thanks to the testing of variables related to the supply side (adult females), the demand side (adult males) and the scale effect (adult population), which all prove relevant to the number of sex workers throughout EU-28.

Thanks to OLS tests, we checked these estimates according to some reasonable assumptions with respect to supply and demand, in order to avoid major inconsistencies. We acknowledge that adjusted National Accounts may not capture the full magnitude of prostitution, whereas assumptions regarding both customers and prices are disputable. However, we can assess a few plausible figures for prostitution in the EU-28 as follows. Estimate 1A from HIV prevalence (542,000 prostitutes) is consistent with National Accounts, with respect to the demand side and the supply side; it is likely to be a lower bound for prostitution in the EU-28 as of 2010. Although it is less robust and consistent with National Accounts, Estimate $2 \mathrm{~A}$ as highest of the lowest (748,000 prostitutes), is likely to be a middle bound for prostitution, whereas Estimate 1B from HIV prevalence $(976,118)$ is quite robust and likely to stand as a high upper bound. Estimate 3B that was extrapolated from victims of sexual exploitation $(768,000$ prostitutes) is lacking both robustness and consistency. Estimate $2 \mathrm{~B}$ as the lowest of the highest $(1,310,000$ prostitutes) is not an unreliable upper bound for prostitution in the EU-28 as of 2010; otherwise, it would imply the National Accounts underestimate prostitution by factor 2.4 , which seems quite unlikely.

There are limitations in our study that better data should overcome to some extent.

The first limitation is that of any cross-section analysis upon a small sample. In the absence of a reliable database for prostitution, we did not use panel data; hence, we did not address the dynamics of prostitution. We have no robust variable addressing the demand side such as a proxy for customers that deserves dedicated surveys upon sexual behavior as well as National Accounts data for prostitution expenditure. Last, we have little evidence regarding either the share of sexual exploitation (namely coercive prostitution) vs. non-coercive prostitution, or the share of salaried vs. self-employed prostitutes that deserve dedicated surveys.

\section{References}

ABRAMSKY, J. and DREW, S. (2014). Inclusion of Illegal Drugs \& Prostitution in the UK National Accounts, May. Office for National Statistics, London: UK

ADAIR, P. (2012). Non Observed Economy and informal employment in the UE countries: A comparison of estimates and determinants. In Pickhardt M. and Prinz A. (eds), Tax Evasion and the Shadow Economy, chap. 5, pp. 83-121, Edward Elgar: UK. 
AKEE, R., BEDI, A., BASU, A. K., and CHAU, N. H. (2011). Transnational trafficking, law enforcement and victim protection: A middleman's perspective. IZA Discussion Paper No. 6226, December.

CARAEL, M., SLAYMAKER, E., LYERLA R., and SARKAR S. (2006). Clients of sex workers in different regions of the world: hard to count. Sexually Transmitted Infections Vol. 82, Suppl. 3, pp. 26-33.

CHARPENEL, Y. ed. (2013). Sexual Exploitation Prostitution and Organized Crime, www.fondationscelles.org/pdf/rapport_mondial/sexual_exploitation_prostitution_Fondation_Scelle s.pdf

CHO, S-Y., DREHER, A. and NEUMAYER, E. (2013). Does Legalized Prostitution Increase Human Trafficking? World Development Vol. 41, pp. 67-82.

DELLA GIUSTA, M., DI TOMMASO, M. L. and STRØM, S. (2009). Who is watching? The market for prostitution services. Journal of Population Economics Vol. 22, pp. 501-516.

DUNN, M., AKRITIDIS, L. and BIEDMA, L. (2014). The impact of ESA 2010 on key indicators of the national accounts in Europe. Eurona Vol. 2, pp. 7-27

EDLUND, L. and KORN, E. (2002). A theory of prostitution. Journal of Political Economy Vol. 110, No 1, pp. 181-214.

EUROSTAT (2012). Europe in figures. Publications Office of the European Union: Luxembourg.

EUROSTAT (2013a). Trafficking in human beings. Publications Office of the European Union: Luxembourg.

EUROSTAT (2013b). European System of Accounts -ESA 2010. Publications Office of the European Union: Luxembourg.

FARMER, A. and HOROWITZ, A. W. (2013). Prostitutes, Pimps, and Brothels: Intermediaries, Information, and Market Structure in Prostitution Markets. Southern Economic Journal. Vol. 79, No 3, pp. 513-528.

FSO (2014). Statistisches Bundesamt [Federal Statistical Office]. Germany

GYOMAI, G. and VAN DE VEN, P. (2014). The Non Observed Economy in the System of National Accounts. OECD Brief, 18, June. OECD, Paris: France.

HAKIM, C. (2015). Supply and Desire: Sexuality and the sex industry in the $21^{\text {st }}$ century. IEA Discussion Paper No.61, August. London: UK.

ILO (2012). ILO Global estimate of forced labour - Results and methodology. Indicators of Forced Labour. Special Action Programme to Combat Forced Labour. International Labour Office, Geneva: Switzerland.

ILO (2009). Operational indicators of trafficking in human beings Results from a Delphi survey implemented by the ILO and the European Commission, September, Geneva: Switzerland.

IMMORDINO, G. and FLAVIANO RUSSO, F. (2014). Regulating Prostitution: A Health Risk Approach. CSEF - Centre for Studies in Economics and Finance, November, University of Naples: Italy. 
JOHNSON, A.M., MERCER, C.H., ERENS, B., COPAS, A.J., MCMANUS, S. and WELLINGS, K. (2001). Sexual behaviour in Britain: partnerships, practices, and HIV risk behaviours. Lancet, Vol. 358, No 9296, pp.1835-42.

KARA, S. (2009). Sex Trafficking: Inside the Business of Modern Slavery. Columbia University Press, New York: USA.

KARA, S. (2011). Designing More Effective Laws Against HumanTrafficking. Northwestern Journal of International Human Rights, Vol. 9, No 2, pp. 123-147.

KAZEMIER, B., BRUIL, A., VAN DE STEEG, A. and RENSMAN, M. (2013). The contribution of illegal activities to national income in the Netherlands. Public Finance Review, Vol. 41, No 5, pp. 544577.

KAZEMIER B. and RENSMAN M. (2015) De illegale economie en nationaal inkomen". Justitiële verkenningen, Vol. 41, No 1, pp. 37-50. Wetenschappelijk Onderzoek- en Documentatiecentrum van het ministerie van Veiligheid en Justitie en Boom Juridische uitgevers.

JAKOBSSON, N. and KOTSADAM, A. (2013). The law and economics of international sex slavery: Prostitution laws and trafficking for sexual exploitation. European Journal of Law and Economic. Vol. 35, No 1, pp. 87-107

LEE, S. and PERSSON, P. (2015). Human trafficking and regulating prostitution. Unpublished manuscript. November, Social Science Network.

MALthUS, T. R. (1798). An Essay on the Principle of Population, Liberty Fund, Inc., 2000. http://oll. libertyfund.org/titles/311

MANDEVILLE, B. (1724). A Modest Defence of Publick Stews. In Primer I. ed. (2006) Bernard Mandeville's "A Modest Defence of Publick Stews". 42-100. Palgrave MacMillan: New York: USA.

MENDES BOTA, P. (2014). Prostitution, trafficking and modern slavery in Europe, Doc. 13446, March 20. www.assembly.coe.int

PROSTCOST (2015) An estimate of the social and economic cost of prostitution in France. May, Mouvement du Nid - Psytel, Paris: France.

PRÜSS-USTÜN, A., WOLF, J., DRISCOLL, T., DEGENHARDT, L., NEIRA, M. and CALLEJA, J.M.G. (2013). HIV Due to Female Sex Work: Regional and Global Estimates. PloS ONE Vol. 8, No 5, pp. $1-7$.

SAVONA, E. U. and STEFANIZZI, S. eds. (2007). Measuring Human Trafficking: Complexities and Pitfalls, Springer: New-York: USA..

SCHULZE, E. (2014). Sexual exploitation and prostitution and its impact on gender equality. Policy Department C: Citizens' Rights and Constitutional Affairs. European Parliament, Brussels: Belgium

TAMPEP (2010). National mapping reports, European Network for HIV/STI Prevention and Health Promotion among Migrant Sex Workers, TAMPEP International Foundation: Netherlands

UNODC (2010). Trafficking in Persons Report 2010. United Nations Office on Drugs and Crime, Vienna: Austria. 
UNODC, (2014). Global Report on Trafficking in Persons, country profiles Western and Central Europe. United Nations Office on Drugs and Crime, Vienna: Austria.

VANDEPitTE, J., LYERLA, R., DALlABetTA, G., CRABBE, F., AlARY, M., and BUVE, A. (2006). Estimates of the number of female sex workers in different regions of the world. Sexually Transmitted Infections, Vol. 82, Suppl. 3, pp. 8-25.

VAN DE VEN, P. (2015). New standards for compiling national accounts: what's the impact on GDP and other macro-economic indicators? OECD Brief, 20, February, OECD, Paris: France. 